\title{
Palakesi obiugri mütoloogiast II
}

\author{
Aado Lintrop
}

Kuldnaine. 1562. aastal, kümme aastat pärast seda, kui Ivan IV oli Kaasani vallutamisega pannud aluse vene impeeriumile, trükiti Londonis Anthony Jenkinsoni poolt uus Venemaa kaart, millelt leiame Obi alamjooksule paigutatud Jugramaa. Samasse on joonistatud madonnasarnase iidoli ees põlvitavad jugralased. Lisatud tekst ütleb:
"Zlata Baba, see on kuldne eit obilaste juures, jugralaste poolt hardalt austatud. Sellelt iidolilt küsib preester nõu, mida neil tuleb teha või kuhu minna, ning tema (imepärane ennustaja) annab mõnedele nõuküsijatele vastused, ja teatud tagajärjed järgnevad neile."

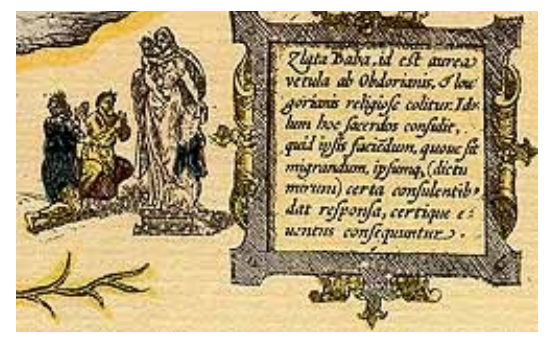

Esimesed teated obilaste kuldnaisest leiduvad XIV saj. Novgorodi kroonikas viitega Permi Stefanile. Järgmiseks teatavad kuldsest iidolist XVI saj. Moskva suurvürsti alamad, kelle ülesandeks on kirjeldada laieneva Venemaa kauba- ja sõjateid. Teadaolevalt esimese eurooplasena mainib kuldset naist Krakovi ülikooli professor Miechovi Mathias. Veel räägib kuldnaisest seoses Jermaki retkega Siberi kroonika: Ivan Brjazga nimeline Jermaki ataman jõudis 1582. aastal Belogorje kanti, kus võitles obiugrilastega, kes väidetavasti kaitsesid oma peamist pühadust - kuldnaist. (Vt. Karjalainen 1918: 243-245, Shestalov 1987: 347.) Ka Grigori Novitski väidet, et Belogorjes oli varem koos vaskse hanega ühes kultusehoones ka "kõige suurem tõeline iidol", ning et ebausklik rahvas "nüüdsel ajal, mil iidolikummardamist välja juuritakse, säilitas selle puusliku ja viis Kondasse," on peetud kuldnaise kohta käivaks (Novitski: 61). Tegelikult pole ükski eurooplane seda iidolit näinud ja arvatavasti pole seda sellisel kujul (inimesekõrgune kullast naine) kunagi olnud. Ainet sedalaadi kuulujuttude levikuks andis obiugrilaste folkloor, kus Kaltesh-eekvat tavaliselt kuldseks nimetati (vt. artikli eelmises osas tsiteeritud laulu).

Mainitud hane-iidoli kohta aga kirjutas Novitski: "Nende poolt väga jumaldatud iidol hani on hane kujul vasest valatud, tema jõle elamu asub Belogorje külas suure Obi jõe ääres. Nende ebausu kohaselt austatakse (seal) veelindude - luikede, hanede ja muude vee peal ujuvate lindude - jumalat... Templis on ta aujärg erinevast kalevist, lõuendist ja nahkadest pesa taoliselt punutud, sellel istubki seal elutsev hirmutis, kes on alati suuresti austatud, kõige enam aga ajal, mil algab veelindude püüdmine... See iidol on niivõrd kuulus, et kaugetest küladest tullakse oma jõledaid ohvreid tooma, mõnel juhul kariloomi, aga peamiselt hobuseid tuues, olles kindlal veendumusel, et see (iidol) on paljude hüvede andja, aga peamiselt annab külluse veelindude saamiseks..." (Novitski: 61.) Võib lisada, et hani oli obiugrilaste ühe populaarseima jumaluse - Maailmavaatava Mehe - üks esinemiskujusid ning et Belogorjet peetakse mõnel pool tänapäevalgi tema elupaigaks.

Maailmavaatav Mees (mansi Mir-susne-hum, handi Mir shääviti ho, tuntud ka kui Mastõr, Ootõr, aga ka Mikolai, Sorni-iki, Postojank-iki jne.), Temaga seotud ettekujutusi on kahtlemata mõjutanud nii Püha Jüri kui ka Nikolai Imetegijaga seotud uskumused. Vladimir Toporov leiab obiugrilaste Maailmavaatavas mehes mitmeid india-iraani kosmilise seaduse, korra- ja päikesejumala Mitra jooni (Toporov 1989: 169-175). Järgmine mansi laulukatkend seostab Maailmavaatava Mehe töepoolest päikese ja kuuga ning aastaaegade vaheldumisega: 
Noorem vend kuldne Ootõr

astub õue, laseb patsid alla -

ühe suudmega seitse Obi voolab,

ühe suudmega seitse merd tõuseb.

Tema patsides seisab päike,

tema patsides seisab kuu.

Seitsmest Obist, seitsmest merest tulles

seitse kuldsete selgadega põrnikat

üles tõusevad,

tema juustes oma selgasid soojendavad.

Tema juuste väel on suvi ja on talv.

Kogu maailmas elavad

vaeselt kängitsetud, vaeselt rõivastatud

inimesed kõik nende abil

nüüdse päevani püsivad.

(Great Bear 1993: 109-110.)

Nagu eespool juba räägitud, esineb muistendites motiiv sellest, kuidas Maailmavaatav Mees sündis taeva ja maa vahel. Tüüpiline on motiiv sellest, kuidas taevase isa noorim poeg võidab isa poolt korraldatud võistlusel vanemaid vendi (näiteks suudab ta esimesena siduda oma hobuse hõbeposti külge - Toporov 1989: 171 < Gondatti 1888). Tshernetsovi järgi oli Maailmavaataval Mehel sada naist ja sada poega, kellest said alguse shamaanid (Tshernetsov 1987: 155). Tema oligi see jumalus, kelle poole obiugri shamaanid kõige sagedamini pöördusid. Näiteks kirjutab N. L. Gondatti manside kohta:

"Kõige sagedamini kutsutakse kohale Maailmavaatav Mees, sest ta on inimeste eest hoolitsev ja neile lähimal olev jumal. Teda kutsutakse peamiselt öösiti, kui ta on sooritamas oma ringkäiku maa peal. Selleks kustutatakse majas tuli, shamaan lööb mõne korra trummi, mispeale saabub täielik vaikus. Vaikuses on selgesti kuulda hobusekapjade plaginat, mis lõpeb jumala majjaastumist märkiva mütsatusega. Natukese aja pärast on kõik möödas ja shamaan, kes sageli lamab pikali põrandal, hakkab jumala sõnu edasi rääkima. Väga sageli asetatakse ennustamise ajaks maja ette hõbedast või mõnest muust metallist taldrikud, et jumala hobune ei peaks seisma palja maa või lume peal." (Karjalainen 1918: $580<$ Gondatti 1888.)

Põhjamansi karupeiete etenduslaulus kutsutakse Maailmavaatavat Meest appi selliste sõnadega:

"Meie sooblinahkse kiiduväärse palve

kuhu laiali laotame?

Valgeveelise toidurikka Obi ülemjooksul sjopõr-hõbedases (1) ülestõstetud linnas elatakse,

sulahõbedases ülestõstetud linnas elatakse.

Oma musta looma(naha) kattelises majas, punase looma(naha) kattelises (2) majas elamise ajal, seitsmes haldjate (maailma)osas tiirlev kuldne mees,

su järvevee voolamisele sarnanev meel ilmugu!

Seitsme ühejalgse laua ümber tiirlemise ajal, meie ju palutud hädapalvet sa kuule!

Oma musta looma kattelised varrukad, oma punase looma kattelised varrukad

üle soobliste õlgade et viskaksid!
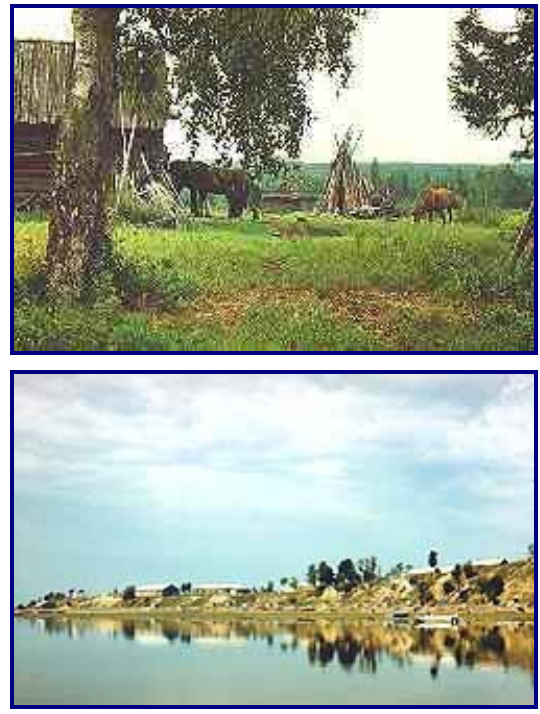
Oma maad vaatava, vett vaatava püha looma selga,

sapsudest kirju püha looma selga,

kuldkandiga püha sadula et saduldaksid, hõbekandiga pühasse sadulasse et istuksid!

(Kannisto, Liimola 1959: 36-37.)

Steinitzi poolt üles kirjutatud handi karupeielaul tutvustab Maailmavaatavat Meest ja ta elupaika üsna üksikasjaliselt:

Hommiku ajal kasvanud

kuldse muruga kasvatatud neemel, õhtu ajal kasvanud

kuldse rohuga kasvatatud neemel;

kevadmetsisekuke sulgedega ülepuistatud küngastel, sügismetsisekuke sulgedega ülepuistatud küngastel; jooksva pilve kõrgusel, sammuva pilve kõrgusel minu kuukirja püha maja minu päikesekirja püha maja

kuldse keti kallis otsas seal see ripub, kuldse hõbeda kallis otsas seal see ripub. (3)

Lõunakõrist kõriline tuul kui tõuseb, väikese hõbeda kõlina kõlal suudmepoolse Obi kalli vee poole seal see liigub.

Põhjakõrist kõriline tuul kui tõuseb, suure hõbeda kolina kõlal lõunapoolse Obi kalli vee poole seal see liigub.

(Steinitz 1939: 339-340.)

Samas laulus kirjeldatakse, kuidas Maailmavaatav Mees istub oma kuldkabjalise laua taga ja kirjutab seitset kuldset ornamenti, kuut kuldset ornamenti oma pühasse kevadistest oravanahkadest raamatusse, pühasse sügisestest oravanahkadest raamatusse. Valvsa auli terava kõrvaga kuulab ta võruna keerlevat haldjate ilma: palju väikesekabjalisi ohvriloomi on talle kisendanud, palju väikeselakalisi ohvriloomi on talle kisendanud. Oma püha kuukirju hobuse seljas, oma püha päikesekirju hobuse seljas ratsutab ta ümber rõngasvõruna keerleva haldjate ilma.

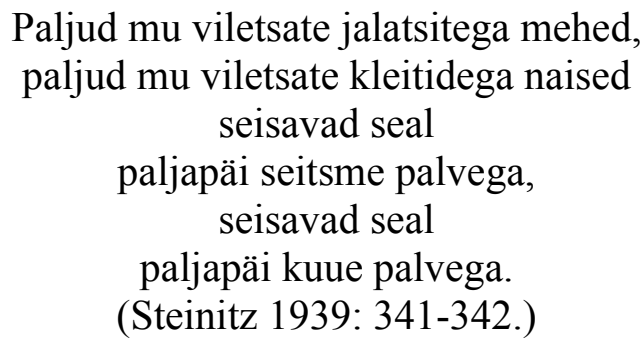

Teises laulus räägitakse pikemalt tema ülesannetest - sellest, kuidas ta pidevalt jälgib maapealset elu ning kannab hoolt inimeste eest. Ta on vahendajaks inimeste ja Kalteshi vahel, annab talle edasi inimeste abipalved ja kutsub teda üles hädasolijaid aitama:

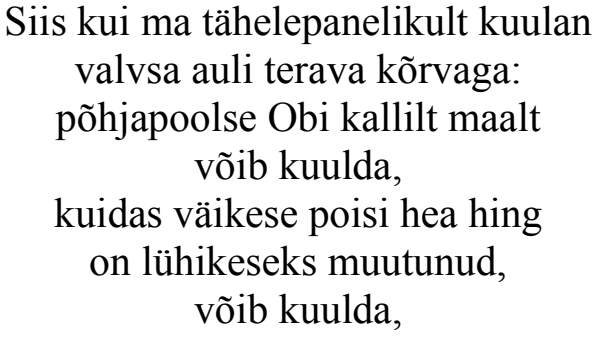

suunan ma nüüd karusnahana pehme palve:

"Tütarlapsena kaunis vihane väike naine, kuula ometi!

Oma sülelise kasuka rüpest võta (palve) välja, oma käiselise kasuka varrukast 
kuidas väikese tüdruku hea hing on lühikeseks muutunud. (4)

Väikeste poiste peale halastav haldjas selle nime all tuntakse mind, väikeste tüdrukute peale halastav haldjas selle nime all tuntakse mind.

Tütarlapsena kauni Kalteshi poole, oma ema poole, oma ema poole suunan ma nüüd sooblinahana pehme palve, võta (palve) välja!

Põhjapoolse Obi kallil maal

on väikese poisi hea hing

lühikeseks muutunud,

on väikese tüdruku hea hing

lühikeseks muutunud.

Edasimääratud iga

pead (lapsele) edasi määrama, edasielamisiga

pead (lapsele) edasi ette kirjutama!"

(Steinitz: 356-358.)

Kuid Mir-susne-hum oli sageli ka os'mar-hum - vembumees. Tal oli saav-sov vaarim kent - paljudest nahkadest õmmeldud müts, mis tegi nähtamatuks. Kui ta oli juba väga palju vägimehi tapnud ja muud halba korda saatnud, ütles Toopal ooika: "Aitab küll, nüüdsest saad kõigi inimeste kaitsjaks." (Tshernetsov 1987: 153-155.) Juttudes esineb sageli nimedega Eekvapõgris'/Eekvapõg - Eide (resp. naise) Poeg, Naise Nõbu (vennapoeg). Viimane on Maailmavaatava Mehe profaniseeritud vaste, kes kordab jumaluse loomisaegade trikke inimestele tuttavas kultuurikeskkonnas. Tõepoolest algavad jutud Eekvapõgris'est sageli vormeliga: Taevase linna, kuninga linna lähedal elab Naise Poeg koos oma vanaemaga (vt. Muinasjutud 1991: 6, 10). Või - Elab Naise Poeg koos oma vanaemaga. Kuigi käib jahil, aga midagi ei saa kätte (ibid: 15). Tuleb rõhutada, et sedalaadi lugude taevane linn, kuninga linn, kuigi asustatud kaupmeeste, pappide, sõdurite ja muu "maise" rahvaga, ei pruugi siiski veel maine linn olla. Oli ju Numi-Toorumilgi taevas oma linn. Üks tüüpiline mansi jutt Naise Pojast algab nõnda:

"Elasid väga vaesed talupojad, eite-taati. Üks päev jõudis kätte, kiriku ukse kohal oli kiri: kellel lapsi pole, see sisse astuda ei tohi. Nad läksid sinna - ei tohi sisse astuda! Taat ütleb: "Noh, kõik, sisse minna ei tohi, läheme koju, palume jumalat, et las saame lapse." Nad on juba vanad, aga ikka paluvad.

Tulid koju, palusid jumalat. Nad ei elanud kuigi kaua, kui eit juba sünnitas poja. Vanasti oli nii - kui laps sünnib, viiakse kirikusse. Nende last ei taha keegi ristipojaks võtta. Siis ütles tsaar: "Ma võtan (ta ristipojaks)."

Eide ja taadi poja nimi on Nikolka. Seejärel laulude inimene, muinasjuttude inimene kas kaua kasvab? Kiiresti kasvas, jõudis jooksmise ikka. Ta läks tsaari maja akna alla, seal jookseb, tatine-ilane poisike. Tsaar nägi, koputas aknale: "Astu sisse!". Ta astus sisse, tsaar küsis: "Minu ristipoeg, kas see oled sina?" Ta ütles: "Mina." Siis annab tsaar talle saapad, ilusad läikivad saapad. Poiss mõtleb, ütleb: "Peab koju minema, kodus mind vist otsitakse, ammu tulin kodust ära." Koju minnes (näeb): eit läheb. Ta võttis ühe saapa kiiresti jalast ja viskas. Eidel on pull, viib pulli. Nüüd eit võttis saapa kiiresti üles, silmitses seda, ütles: "Mis ma ühe saapaga teen?" Jättis selle sinnasamasse maha. Poiss mõtles: "Nüüd ma jooksen." Läks eide tee peale ja võttis teise saapa jalast. Eit mõtles: "Kui nüüd teise ka siit leiaksin." Eit seob oma pulli sinna kinni, ütleb: "Olgu, lähen tagasi." Ta läks tagasi, Nikolka võttis pulli, pani saapad jalga ja läks koju." (Rombandejeva 1979: 145.) 


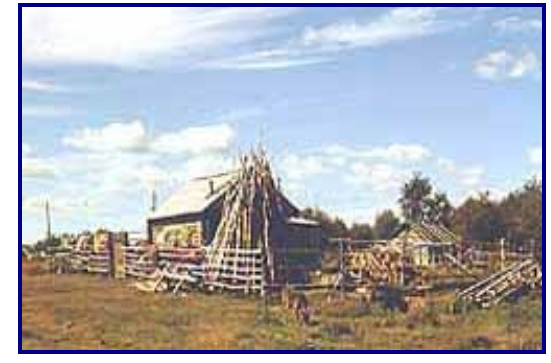

Handi elamu koos kõrvalhoonetega. Ust-Voikari küla. Foto A. Lintrop 1989.

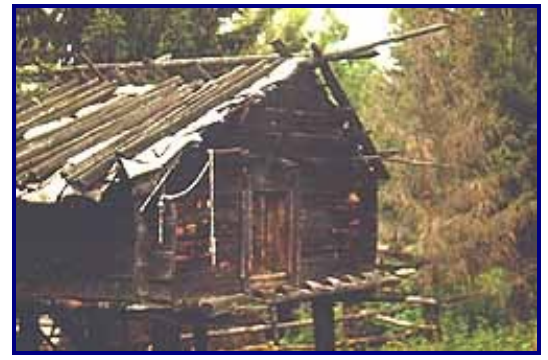

Mansi sammasait Ljapini ääres.

Foto A. Lintrop 1977.

Ka karupeielauludes esineb Naise Poeg lollikese Ivani moodi tegelasena:

Külatanuma vihane mees Eekvapõg, linnatanuma kuulus mees Eekvapõg paljudel Toorumi loodud päevadel tanumalise küla tanumal kinnihoidmismängu mängis, löömisemängu mängis koos küla paljude lastega, koos linna paljude lastega. Haldja ilusal külluslikul päeval, Isanda ilusal külluslikul päeval Linna Isanda-isa (5) kaks poega koju ruttasid.

Üks neist meestest ütles:

"Ma leidsin soolooma maja, ma leidsin metslooma maja, (6) meie kaks läheme homme hommikul (jahile)!"

Külatanuma kuulus mees Eekvapõg, linnatanuma vihane mees Eekvapõg terava kuulmisega mehena (seda) kuulis.
Linna Isand-taadi poegade juurde ta ruttas: "Noh, mehed, te leidsite maja, kus istub sooloom, te leidsite maja, kuhu metsloom on sisse astunud.

Homme loodaval kullana ilusal päeval mind (koos) vöötatud kaaslastega (7) võtke kaasa!" Linna Isand-isa pojad ütlesid: "Milline kõnts! Me ei võta!" Siis hakkas ta nutma. Üks neist meestest ütles:"Olgu, võtame (kaasa)!

Ta rõõmustas, jooksis koju.

Kui ta tädi sellest teada sai, leidis ta kolmekandilise kandinõela, teritas selle ära,

põdrapulli keele (pikkuse) osjase oda tekitas, loomakeele (pikkuse) osjase oda tegi.

Kui ta tädi sellest teada sai, teritas ta nürida talvakese ära, põdrapulli abaluu suuruse kirve siis tekitas, looma abaluu suuruse kirve siis tekitas.

(Kannisto, Liimola 1958: 186-187)

Loomulikult põgenevad Linna Isand-taadi pojad neid ründava karu eest ja Naise Poeg on see, kes looma tapab.

Läheb edasi...

\section{Kirjandus:}

Great Bear 1993. The Great Bear. A Thematic Anthology of Oral Poetry in the Finno-Ugrian languages. Pieksamäki.

Kannisto, A., Liimola, M. 1958. Wogulische Volksdichtung IV. Bärenlieder. SuomalaisUgrilaisen Seuran Toimituksia 114. Helsinki.

Kannisto, A., Liimola, M. 1959. Wogulische Volksdichtung V. Aufführungen beim Bärenfest. Suomalais-Ugrilaisen Seuran Toimituksia 116. Helsinki.

Karjalainen, K. F. 1918. Jugralaisten uskonto. Suomensuvun uskonnot III. Porvoo. 
Muinasjutud 1991. Skazki narodov Severa. Leningrad - Hantõ-Mansiisk.

Novitski = Novitskij G. Kratkoe opisanie o narode ostjackom. Studia uralo-altaica III. Szeged 1973. Viidatud on ungarikeelsele tõlkele lisatud faksiimiletrükki 1941. aastal Novosibirskis ilmunud raamatust - Novitski G. Kratkoje opissanije o narode ostjatskom 1715.

Rombandejeva J. I. 1979. Sintaksis mansiiskogo (vogulskogo) jazõka. Moskva.

Schmidt, É. 1989. Bear Cult and Mythology of the Northern Ob-Ugrians. Uralic Mythology and Folklore. Budapest.

Shestalov 1987 = Shestalov J. Taina Sorni-nai. Moskva.

Steinitz, W. 1939. Ostjakische Volksdichtung und Erzählungen aus Zwei Dialekten. 1. Teil. Opetatud Eesti Seltsi Toimetused XXXI. Tartu.

Toporov, V. N. 1989. About a Probable Ob-Ugrian Reflection of the Iranian Mithra. Uralic Mythology and Folklore. Budapest.

Tshernetsov V. T. 1974. Bärenfest bei den Ob-Ugriern. Acta Ethnographica Academiae Scientiarum Hungaricae, tomus XXIII, fasciculi 2-4, Budapest, pp. 285-319.

Tshernetsov V. T. 1987. Istotshniki po etnografii Zapadnoi Sibiri. Tomsk. 
1. Sjopõr-hõbe - tänapäeval tähenduse kaotanud omadussõnad sjopr ja kam esinevad hõbeda iseloomustamiseks nii mansi kui ka handi laulude paralleelvärssides. Tõenäoliselt on need tähenduselt lähedased mansi lauludes hõbeda kohta kasutatavate omadussõnadega s'alõg 'voolav, sula' ja mor 'helisev, kõlisev'.

2. Paralleelvärssides esinevad väljendid seem(õ)l ui, võgr ui tähistavad koos kõikvõimalikke karusloomi ja -nahku.

3. Uskumuste kohaselt elab Maailmavaatav Mees maa ja taeva vahel rippuvas majas. Vrd. ka eelmise näite värssidega, kus rägigitakse hõbedasest ülestõstetud linnast.

4. Väljend hing on lühikeseks muutunud tähendab seda, et inimene hakkab surema.

5. Nagu edaspidisest selgub, on tegemist Linna Isand-taadiga (mansi Uusõn-ootõr-ooika), kes on obiugrilaste muistendites, mütoloogilistes lauludes ja muinasjuttudes sageli esinev tegelane.

Eekvapõgris'e juttudes esineb ta mõnikord Naise Poja vastasena (vt. Muinasjutud 1991: 15-20).

Kuigi Éva Schmidt näib teda pidavat omaette üleloomulikuks olendiks, jääb tekstidest mulje, et Linna Valitseja-taat on pigem erinevate piirkondlike (maalinnadega seostuvate) haldjate üldnimi. Teda on seostatud ka Püha Linna Taadiga.

6. Sooloom ja metsloom on tüpilised karu tähistavad eufemismid obiugrilaste folklooris.

7. St täiskasvanud meestega. 